\title{
Agriculture awareness among rural school going adoloescents as per their socio-personal determinants
}

Received: 20.05.2016; Revised: 20.10.2016; Accepted: 01.11.2016

See end of the paper for authors' affiliations

\section{ASHA CHAWLA}

Department of Human Development, College of Home Science, Punjab

Agricultural University, LUDHIANA (PUNJAB) INDIA
ABSTRACT : Agriculture has always been a significant factor in the sustainability and development of human society. Unfortunately, the important role of agriculture as a foundation for a secure and durable civilization is not always apparent to those outside of agriculture. The present research was framed to study socio-personal characteristics and gender difference in awareness regarding agriculture among rural school going adolescents and to study the correlation of socio-personal characteristics and gender differences in awareness regarding agriculture among rural school going adolescents. A sample comprised of 120 rural school- going adolescents was purposively selected from two villages of Ludhiana district. Socio-economic status scale (AICRP) has been used to measure the socio-economic status of the respondent. Self- structured questionnaire was used to gather information regarding awareness level with respect to agriculture. Results revealed that awareness level of adolescent girls about agriculture was comparatively higher than their counterparts. Correlation analysis also found that there is no significant relationship in respondents' socio-economic characteristics and their awareness level regarding agriculture.

KEY WORDS: Agriculture awareness, Adolescents, Socio-personal characteristics

- HOW TO CITE THIS PAPER : Kanwar, Vandana, Chawla, Asha and Princy (2016). Agriculture awareness among rural school going adoloescents as per their socio-personal determinants. Asian J. Home Sci., 11 (2) : 382-386, DOI: 10.15740/HAS/AJHS/11.2/382-386. 